\title{
Techniques of Educational Broadcasting in Distance Mode and Its Social Implication
}

\author{
KM Tajbiul Hasan \\ Dhrupad Communication-media for Education \& Development, Bangladesh
}

Copyright $\mathrm{O} 2018$ by authors, all rights reserved. Authors agree that this article remains permanently open access under the terms of the Creative Commons Attribution License 4.0 International License

\begin{abstract}
Education in distance mode by broadcasting media is still most convenient and cost effective to expand and ensure education for all. To impart education in distance mode through the broadcasting media have some basic fundamentals. A success of educational broadcasting fully depends on the appropriate selection of script for accurate people. Thus, it is an essential component of teaching-learning strategies to achieve various national goals - socioeconomic and cultural. The fundamentals of script writing for educational Television and Radio are same. That is-To whom (Listeners/ Viewers), what (Contests) and what for (Educational goal). Writing for radio and television is very different due the technical and imagination perspective. Both media has its own style and mode of presentation. Education through radio should be very distinct, direct and define. Complex topic, sentences $\&$ words, which create confusion to the listeners, should try to avoid in all concern. On the other hand, like educational radio programs, television programs have the same formats with some extra benefits to add dances, animation, and computer graphics etc. Television has lot of scope to describe the topic in various ways due to its visual support that's why it seems to be flexible than radio. Today these two electronic media stands for development and cooperation. New forms of communication media like Internet, multimedia or mobile phone are considered to the very effective media for distance education. These most advanced technologies may not be applicable for all countries like Bangladesh due to the social-economic condition. So, in Bangladesh considering the social economic reality government has been using radio and television broadcasting for distance education broadly since the last two decades. A significant result has already been achieved in the field of mass education of Bangladesh.
\end{abstract}

Keywords Education Technique, Social -Economic Aspects, Effectiveness and Significance

\section{Introduction}

What is education: "Education" is exchange and transformation of information and communications. Education means improving the quality of life of every one to create efficient, active, productive and profitable manpower. When education imparts in distance mode mainly by broadcasting media, it reform a different characteristics and styles whatever it is formal or non-formal approach. This approach is fully different from other media. The technique of educational broadcasting mainly depends on two parts .At first Production planning - which indicates the proper script development and secondly implication through proper broadcasting.

Script for the broadcasting media is not the same as writing of print media. In general every script writer wants to reach his/her audience with his/her script, which is the main principle in successful communication. But, educational script has a unique writing style. At the same time, Educational script writer cannot behave like a novel writer because the text has to be developed by the producer, the director, subject specialists, researchers and the rest of the team.

\section{Precondition and Treatment of an Educational Script:}

Targeted audience- Listeners/ Viewers: Target audience has to be analyzed and determined in details.

Program type.

Program length.

Presentation style.

Contents - Elements and composition of the program.

Educational goals to be achieved: Program goals have to meet the expectations, needs, cultural background, preferences and characteristics of the target audience. 


\section{Writing Techniques and Procedures of Educational Script:}

David Brinkley, the famous Radio or TV broadcaster in history once said, "In order to be successful in broadcasting media, one must do three things: Learn to write. Learn to write. And learn to write".

"Writing is the best possible way to implement any sorts of idea and thoughts before broadcasting. Especially in the educational broadcasting "writing" is the first and most important section to execute the lessons \& information to the listeners and viewers.

Generally when we read, we see the words, which help us to understand the meaning. But, when we listen, information is delivered usually one word at a time. So, to understand the whole meaning of the sentences, we must retain the first word to the last word in our memory, until the sentence or thought is completed. Listeners and viewers do not have scope to go back for rehearing or reviewing, which they missed the first time.

Broadcast writing is for ear and eye. The sentence of broadcasting media should not be too complex or too long to unfold. If not, the Listeners would be confused or missed the meaning. It is crucial that the broadcast writing be as simple as possible. The following clause may be memorized during writing the script for educational broadcasting both Radio and Television:

1. Sentences \& words, which create confusion to the listeners, should be avoided in all concern. Sentences should not start with long, dependent clauses. Separate sentences should be used instead of dependent clauses. Keep sentences are in short form to the point of oversimplification.

2. Scripts would be written in active voice as per as possible; because nouns and verbs are stronger than adjectives and adverbs. Don't try to impose the listeners/viewers to be acted with the adjectives such as "tragic," "amazing," and "stunning etc." If the original stories belong to these facts, the writer must try to examine his approach by different ways

3. Avoid jargon; use well-known terms

4. The 'lead' is important in broadcast writing. The function of the lead is to alert the listeners/viewers that something is going to be said and shown that is important. But that alert must be simple and interesting.

5. Simplify the topics / stories by simple sentences. Because most of everyday sentences are simple. Broadcast writing must reflect this.

6. Use informal tone by using short sentences and try to make it familiar and friendly style.

7. After discussing an important point, explain on it; illustrate it.

8. Don't try to pack too many information into one program.

9. Give the audience a chance to digest one concept before moving on to another.
It is advised, after completing the primary script, the writer has to concentrate his mind on something else for at least ten minutes. Then go back and review the topics with a fresh perspective. At that point it may be easier to catch and eliminate unnecessary words and phrases. Read the sentences loudly (not under your breath) and rewrite

$\square$ Sentences those are too long

Tongue-twisting or discomfited dialect

Idioms /Phrases that could be taken two ways

Long titles

The basic fundamentals of script writing for educational Television and Radio are same. But the writing for Radio and television is comparatively different due the technical and imagination perspective. Both media has its own style and mode of presentation.

\section{Scripting for Educational Radio:}

\section{"Education is the experience of life itself and radio is the communication of life."}

Radio - is an intimate medium. This is fact, Radio does not demand the virtually exclusive level of audience attention that press or television requires. But listeners can carry radio within them. It can be provide company in the kitchen, or on the factory floor, in a traffic jam on the motorway or in a hostage cell on the outer side of the world. So, on these regards, off all "Mass media", radio offers the greatest potential for building up a one to one relationship with each member of its audience. Thus, People listens radio most of the time in subconscious manner. On the other hand, absence of colour, light and picture is indeed a serious limitation of radio broadcasting; therefore, the Education through radio should be very distinct, direct and define.

Selection of topics is very important for educational radio: As for example the mathematical or scientific terms may not be suitable or appropriate in radio. Topics on literature, history, religion, poetry, basic health, nutrition, laws etc. would be good for educational radio. Because listeners creates an imaginary scene in his mind when they listen a radio programme.

A fruitful educational programme in radio is a true "Word Vision". Generally the listeners' can memorize only $30 \%$ to $40 \%$ content of total programme.

It is very necessary for every educational radio script may be written in three parts first summary of main topics, Secondly brief discussion and finally summarized the whole topic once again.

\section{Scripting for Educational Television:}

As an educator; television is the most effective than other media. Television offers real advantage as a medium for public education. It is not an intimate medium like radio; 
Lot of people can enjoy television all together. However, television is unique, is being able to achieve effects other media cannot. Its language is universal. A single frame or picture can express lot of things rather than millions of words. It has versatile appeal to all level of human feelings.

Like Educational radio scripts, Television scripts have the same formats with some extra benefits to add dances, animation, and computer graphics etc. It can tell a story more compulsorily than radio because of the use of visual imagery. Television script is relatively flexible or more complex and critical than radio. Television has lot of scope to describe the topic in various ways due to its visual support that's why it seems to be flexible than radio.

Educational television script needs creative, unique, conceptualized works in relation to aesthetics and artistic applications.

Television's language is both aural and visual. Due to audio-video are incorporating at the same time, so, fraction of fault or misinterpretation will be totally despoiled the programme.

Nothing is hidden in television programme and viewers have no chance to create any imagination. So, the script should be interlocked video and audio for agreement with the audience.

Provide adequate logical structure; let viewers know where you're going, which concepts are important, and when you're going to change the subject.

\section{Implications of Broadcasting Media in Education:}

"All available instruments and channels of information, communication and social action could be used to help convey essential knowledge and information and educate people on social issues. In addition to the traditional means, libraries, television, radio and other media can be mobilized to realize their potential towards meeting basic education needs for all " [Final report World Conference for All: Basic Learning Needs, Jomtien. Thailand 1990]

It has mentioned earlier that electronic media based educations are an effective means to educate the public for the developing countries of South Asia. In Bangladesh Education is the fundamental to the development. In Bangladesh absence of adequate teaching institutions and qualified teachers are the major factors for all sorts of education.

The government has placed a high priority on it, particularly at primary level. The student teacher ratio is 63 to 1 the worst in Asia. Average student/teacher contact time is 2.5 hours per day, one of the lowest rates of the world. There are lots of problems in the education sectors - among all absence of good teachers are the main reasons. Broadcasting media may come forward on this issue. A good teacher and instructor can teach in classroom in front of a few students but through radio and television it can be reached to the millions of students. So, it is a great advantage to expand education to each and every one. Bangladesh lacks of institutions and good infrastructures for proper education. As for example every year nearly fifteen hundred thousand students pass in the Secondary School Certificate Examination (The biggest public examination in Bangladesh) but due to absence of adequate institutions only two third students can get admission and rest of them had nothing to do before 1993 when Bangladesh Open University (BOU) was established. Problems are as same as for other public examinations. $\mathrm{BOU}$ is the last destination for those. Though BOU provides Education in distance mode but without educational broadcasting it would be somewhat impossible for BOU to expand its service.

\section{Success of GOVT Broadcasting Media in Bangladesh:}

Bangladesh Television (BTV) has a good number of success stories in the term of informal mass education in Bangladesh. Some examples are as follows

"Mati O Manush" is a pioneer television prgramme, starting from mid $1980 \mathrm{~s}$, has created a revolution to the agriculture sector of Bangladesh. Lot of unemployed people finds their way to establish themselves in the agriculture sectors. This program is still ongoing due to extensive people demand.

"Mina" an educational cartoon show has become the most popular one forever, started in 1985. All sorts of most essential basic information \& education have come out from that show.

Two TV serial of late 90s on integrated family planning and Family health service "Shabuj Shathi" and "Shabuj Chhaya" are the best example how Television acts as a Mass Educator.

Evaluation of drama title Shabuj Shathi was carried out by a nationally representative in rural and urban areas.

Sample is surveyed of 10,400 men and women from 15 to 49 years of age (OMQ, 1998). Analysis of the impact of the drama was conducted on a sub sample of 4,566 married women ages 16 to 49 , watched by region and urban/rural residence.

An index of overall health knowledge was constructed from a series of questions about safe motherhood, childhood diseases, HIV/AIDS, nutrition and goiters. The following two graphs are showing the potentiality of this TV serial. 


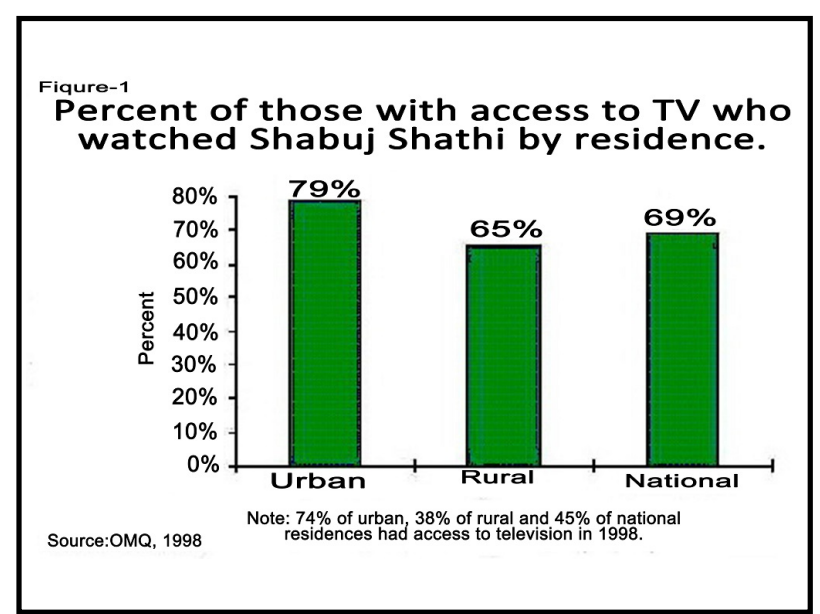

Graph-1

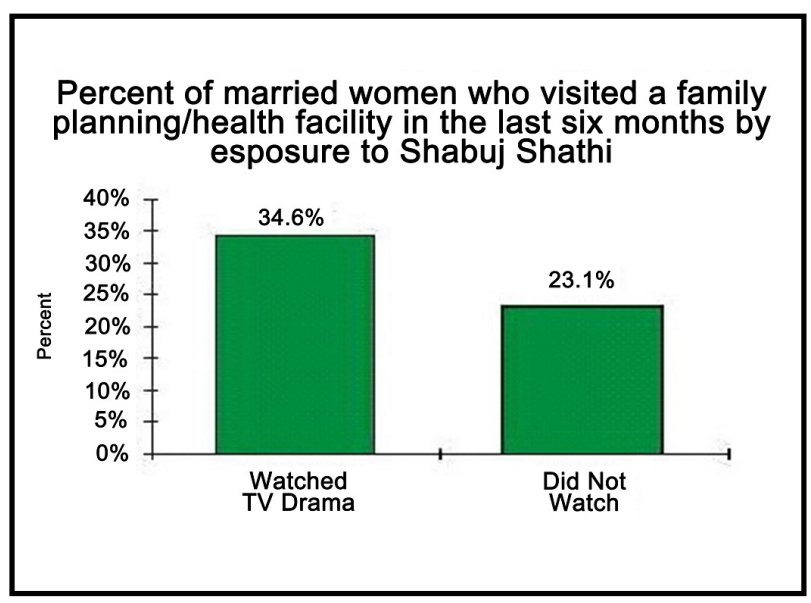

Graph-2

The drama shows "Shabuj Chhaya improved the knowledge and behaviors related to various health issues among men and women.

Exposure to the drama was categorized into three levels: No exposure (having watched none of the 13 episodes), Low exposure (having watched 1-5 episodes) and High exposure (having watched 6-13 episodes

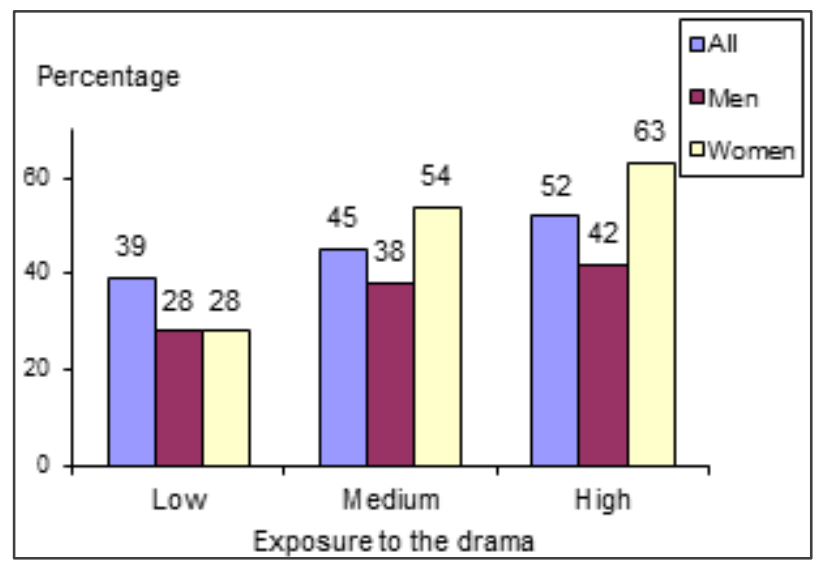

Figure 1. Percentage of people who could name at least a symptom of pneumonia by exposure to the drama and gender, Bangladesh, 2000

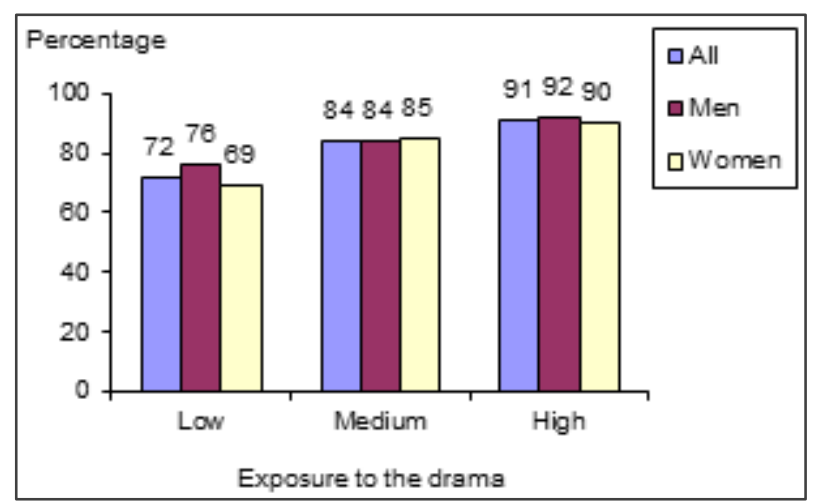

Figure 2. Percentage of people who knew that breast milk should be given to a newborn by exposure to the drama and gender, Bangladesh, 2000

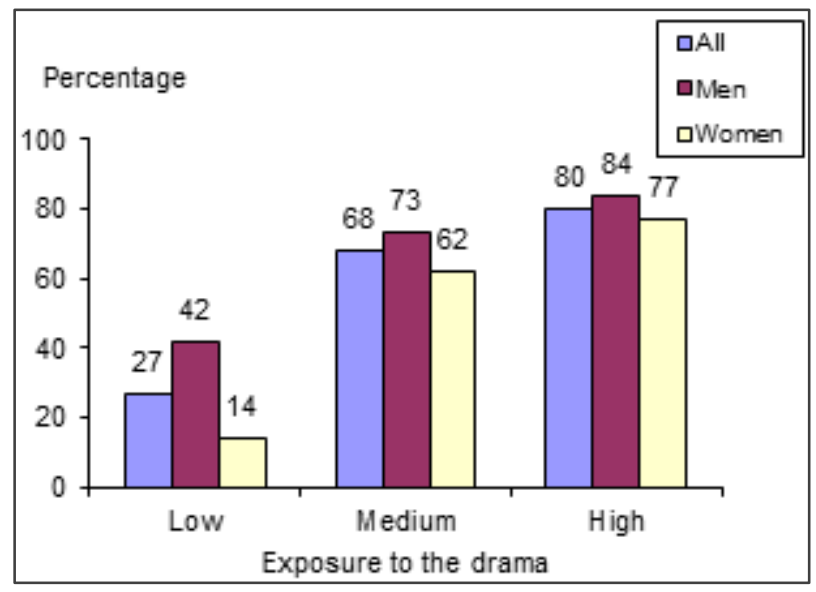

Figure 3. Percentage of people who ever heard of HIV/AIDS by exposure to the drama and gender, Bangladesh, 2000.

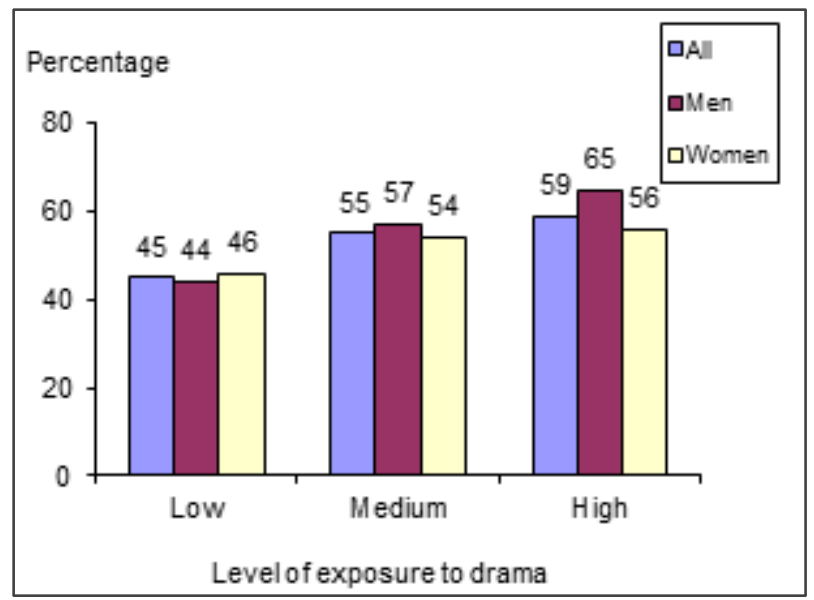

Figure 4. Percentage of currently married people who were using a modern contraceptive by level of exposure to the drama and gender, Bangladesh

These two TV serials on Family planning and Reproductive health education programmes have shown how broadcasting media create a remarkable impact on the people of different category. Due live in a conservative society certainly we fill shy to talk about sex and reproductive health issues. Only Broadcasting media can 
easily break down these social problems.

In Bangladesh the success rate of child immunization programme [EPI -Extensive Programme for Immunization] is higher than any other country of South and South-East Asia. Now Bangladesh is considered to be a "Polio" free country of Asia.

Beside these examples, two recent educational television programs of Bangladesh Television (BTV) have already made an enthusiastic model in educational broadcasting.

BBC Janala (Translation: BBC Window) is a learning English programme for the people of Bangladesh. It launched in November 2009 and is a unique multi-platform to provide affordable education to potentially millions of people in the Bangladeshi-speaking community.

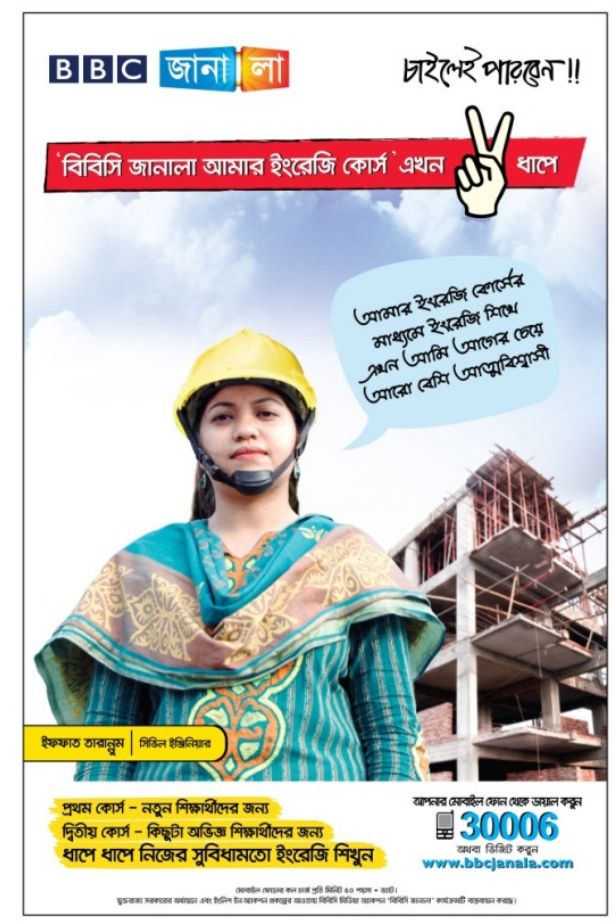

It is a weekly youth entertainment show that places English at the centre of young people's everyday lives. The program broadcast in a prime-time Friday evening slot on Bangladesh Television (BTV) and BTV world (Satellite). It mixes Bangla and English in features, comedy sketches, entertaining educational game show, cartoons and discussions on subjects ranging from climate change to arranged marriage. The programmes provide its 14 million viewers with a fun and accessible way for families to learn English together with the ambition to raise the English language skills of 27 million Bangladeshis by 2017.

BBC Janala's reality TV series Nijey Nijey Shekha (Self learning) is a new programme that helps people across Bangladesh to learn English. Nijey Nijey Shekha follows real people from different parts of Bangladesh, from health workers and beauticians to drivers and waiters; they all share the same passion for learning English. As they work to overcome their fears of learning, each of them has just three days to learn enough English to face their own real-life English challenge.

"123 Sisimpur" is the most popular and edutainment puppet drama shows of Bangladesh Television at the recent time for the children those who are between the ages of 0305 years of old. The first season of 123 Sisimpur premiered on Bangladesh Television in April 2005 and is currently broadcast four days a week. This program has already reached to more than 600,000 Bangladeshi children.

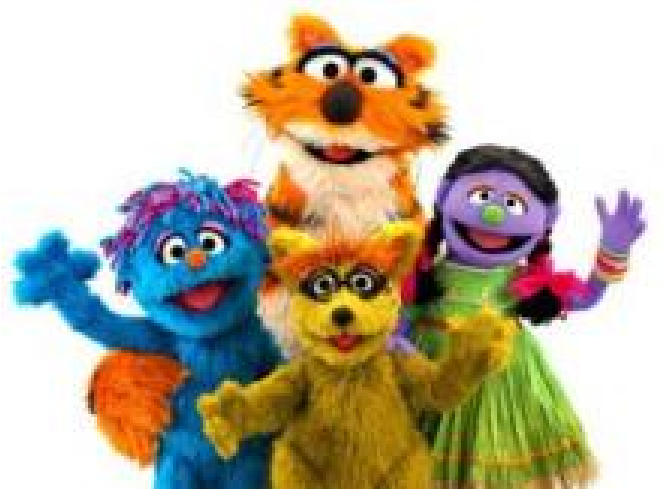

Studies suggest that Bangladeshi children who tune in to 123 Sisimpur are faster to pick up academic skills such as literacy and math, critical aspects of girls' education. Literacy scores of 4-year-olds who watch are 67 percent higher than those who don't. Some viewers are gaining as much as a year's advance in learning.

In a country where fewer than 25 percent of children attend preschool by age 5, Sisimpur delivers vital lessons on literacy, health, and cultural awareness .Of the 67 million adults in Bangladesh who are illiterate, 42 million are women, despite her low-income background.

In general, the research found that "Sisimpur has a positive impact across a variety of domains. The effects remained evident despite stringent statistical controls for numerous potentially confounding factors such as demographic and socioeconomic variables, as well as children's performance prior to viewing the program." The benefits are particularly strong for rural children, girls, and 5-year-olds.

1. Vocabulary - Children who watched Sisimpur outperformed nonviewers in tests of vocabulary. These effects were particularly pronounced for children living in rural areas, girls, and 4- and 6-year-olds.

2. Numeracy Skills - Overall, children who watched Sisimpur were twice as likely as non-viewers to know how to count. Girls who viewed were almost 5 times more likely to know how to count than were girls who did not view. Among 5-year-olds, viewers were over $5 \frac{1}{2}$ times more likely to be able to count than non-viewers. In addition, Sisimpur seemed to have particular benefits in numeric for children in rural areas: Compared to non-viewers, viewers living in rural regions were over 2.5 times more likely to be able to count to 20 , and were able 
to count to higher numbers.

3. Cognitive Skills - Watching Sisimpur was associated with better cognitive skills, both among the sample as a whole, and among 5-year-olds and boys.

4. Life Skills - Watching Sisimpur was associated with a higher likelihood of recognizing disability. The effects of viewing were moderated by gender, such that girls who watched the programme were more likely to recognize individuals with disability and report liking the child with a physical disability than were children who did not watch.

5. The educational messages on life skills also appeared to be especially effective among 5-year-olds: Those who watched the programme were more likely to report making things out of materials in their environment, and to notice physical disability.

6. Cultural Knowledge - Viewing Sisimpur was associated with a higher likelihood of being able to name and recognize local musical instruments, and to know the name of the country.

Taken together, the results provide significant evidence that Sisimpur can make a demonstrable educational impact on young Bangladeshi children. After only 20 days of viewing, children achieved measurable gains in vocabulary, numeracy, cultural knowledge and life skills that exceeded those of children who had not been exposed.

\section{Conclusions}

Technique of educational broadcasting depends on the experience, current demands as well as on the social-economic status, religious believe and value of the society as well as the proper implication of broadcasting how to convey the message to a large audience is likely to be reached.

\section{REFERENCES}

[1] Bangladesh Bureau of Statistic (2004), Ministry of Planning Government of Bangladesh.

[2] Bangladesh Bureau of Educational Information and Statistic -2010 .

[3] Bates, A.W (1984) Broadcasting in Education: an Evolution. Communication and Society Series, London: Constable.

[4] "Education Watch 2001- Renewed Hope, Daunting Challenges, State of Primary Education in Bangladesh" Campaign for Popular Education (CAMPE). University Press, June 2002.

[5] Educational Broadcasting-by Sita Ram Sharma \& A.L Vohra.

[6] "Film and Television in Education"- The handbook of the British Universities Film \& Video council: Second edition. Edited by Chris Dry.

[7] Government of the People's Republic of Bangladesh, Bangladesh Open University Project Performa, 1991-1992, page on $12-13$

[8] "Human Development Report 2001" UNDP, Oxford University Press, 2001.. Impact of Shabuj Chhaya television drama in Bangladesh Television .Key findings from Audience survey - by Mai P. Do, D. Lawrence Kincaid Center for Communication Programs - Johns Hopkins University.

[9] Bates, A.W (1984) Broadcasting in Education: an Evolution. Communication and Society Series, London.

[10] Educational Broadcasting-by Sita Ram Sharma \& A.L Vohra.

[11] "Film and Television in Education"- The handbook of the British Universities Film \& Video council: Second edition. Edited by Chris Dry.

[12] BBC's 2 programmes on BTV. The New Nation (Dhaka,) October 14, 2010

[13] Cultural Impacts of Sisimpur, Sesame Street, in Rural Bangladesh: Views of Family Members and Teachers Academic journal article By Kibria, Nazli; Jain, Sonali Journal of Comparative Family Studies, Vol. 40, No. 1 